\title{
Impact of interleukin-27 on replication of hepatitis $C$ virus
}

This article was published in the following Dove Press journal:

International Journal of Interferon, Cytokine and Mediator Research

2I December 20II

Number of times this article has been viewed

\section{Gaetano Scotto' \\ Adele Giammario' \\ Francesca Campanale' \\ Giovanna D'Addiego' \\ Vincenzina Fazio² \\ 'Clinic of Infectious Diseases, University of Foggia, Italy; ${ }^{2}$ Clinical Chemistry Laboratory, Hospital of Foggia, Italy}

Correspondence: Gaetano Scotto Clinic of Infectious Diseases, University of Foggia, Viale Luigi Pinto I, 7I 100, Foggia (FG) Italy

Tel +39 088I 73209

Email g.scotto@medicina.unifg.it

\begin{abstract}
Recently, different interleukins have been associated with responses to PEGylated interferon and ribavirin and spontaneous clearance of acute hepatitis $\mathrm{C}$ virus (HCV) infection (interleukin [IL]-28B) or with the development of a novel immunotherapeutic strategy for HCV infection (IL-27). IL-27 is a helical cytokine belonging to the IL-6/IL-12 cytokine family with a broad range of anti-inflammatory properties. Some studies demonstrated that IL-27 stimulates hepatoma cells and hepatocytes by inducing a sustained signal transducer and activator of transcription (STAT1 and STAT3) activation. Moreover, IL-27 induces interferon- $\alpha$-like responses including the induction of antiviral genes (ribonucleic acid-dependent protein kinase), oligoadenylate synthetase, and myxovirus protein. In this review we examine the research on IL-27 and its potential role in therapy for HCV, including the capability to inhibit replication of $\mathrm{HCV}$.
\end{abstract}

Keywords: interleukin-27, hepatitis $\mathrm{C}$ virus, chronic liver disease, chronic hepatitis $\mathrm{C}$ infection

\section{Hepatitis C virus}

The hepatitis $\mathrm{C}$ virus (HCV) is a disease with a significant global impact. According to the World Health Organization it is estimated that up to 170 million people ( $3 \%$ of the world's population) are infected with $\mathrm{HCV}$ worldwide. ${ }^{1}$ There are considerable regional differences: prevalence is higher in some Asian and African countries (Egypt has the highest seroprevalence for HCV - up to 20\%) than in North America and Europe. It is estimated that there are 2-5 million HCV-positive people in Europe. In the United States and Europe, chronic hepatitis $\mathrm{C}$ is the most common chronic liver disease. It is currently a leading cause of cirrhosis and a common cause of hepatocellular carcinoma, and as a result of these conditions it is the leading reason for liver transplantation. Coinfection with human immunodeficiency virus (HIV) is common, and rates among HIV-positive populations are higher.

\section{Transmission}

The transmission of HCV is primarily through exposure to infected blood. Risks for transmission include blood transfusion, intravenous drug use, high-risk sexual activity, solid organ transplantation from an infected donor, occupational exposure, birth to an infected mother, and intranasal cocaine use. ${ }^{2}$ Hemodialysis risk factors include blood transfusions, the duration of hemodialysis, the prevalence of HCV infection in the dialysis unit, and the type of dialysis. Sexual activities and practices were initially identified as potential sources of exposure to HCV. Currently, heterosexual vaginal 
intercourse is thought to be a rare means of transmission of hepatitis $\mathrm{C}$ infection. But factors that may increase the risk of HCV infection include greater numbers of sexual partners, a history of sexually transmitted diseases, and failure to use a condom. ${ }^{3}$ The seroprevalence of $\mathrm{HCV}$ in men who have sex with men ranges from about $4 \%-8 \%$, which is higher than the HCV prevalence reported for the general European population. The risk of perinatal transmission of HCV in $\mathrm{HCV}$ ribonucleic acid (RNA) positive mothers is estimated to be $<5 \%$.

\section{The virus}

$\mathrm{HCV}$ is a small (55-65 nm) RNA virus in the Hepacivirus genus of the Flaviviridae family. The HCV particle consists of a core of genetic material (RNA), surrounded by an icosahedral protective shell of protein, and further encased in a lipid (fatty) envelope of cellular origin. Two viral envelope glycoproteins, E1 and E2, are embedded in the lipid envelope. $\mathrm{HCV}$ is a virus with an RNA genome of approximately $9600 \mathrm{bp}$ in length. ${ }^{4}$ Most of the genome forms a single open reading frame (ORF) that is translated to produce a single protein product, which is then further processed to produce smaller active proteins. Short untranslated regions (UTRs) at each end of the genome are required for replication of the genome. The five prime (5') UTR has a ribosome binding site that starts the translation of a very long protein containing 3011 amino acids. This large preprotein is later cut by cellular and viral proteases into the ten smaller proteins - three structural (core, E1, and E2) and seven nonstructural (p7, NS2, NS3, NS4A, NS4B, NS5A, and NS5B) proteins, that allow viral replication within the host cell, or assemble into the mature viral particles. ${ }^{5,6}$

\section{The genotypes}

Comparison of nucleotide sequences of variants recovered from infected individuals in different risk groups for infection and from different geographical regions has revealed the existence of at least six major genetic groups ${ }^{1-6}$ and several subtypes (represented by letters). ${ }^{7}$ Subtypes are further broken down into quasi-species based on their genetic diversity. These genotypes differ by $31 \%-34 \%$ in their nucleotide sequences, whereas subtypes differ by $20 \%-23 \%$ based on full-length genomic sequence comparisons. ${ }^{8}$ The preponderance and distribution of HCV genotypes varies globally. In the United States and Western Europe genotypes $1 \mathrm{a}$ and $1 \mathrm{~b}$ are most common, followed by genotypes $2 \mathrm{a}, 2 \mathrm{~b}$, and $3 \mathrm{a}$. Genotypes 4 and 5 are found almost exclusively in Africa and genotype 6 in Southeast Asia. Genotype is clinically important in determining potential response to IFN-based therapy and the required duration of such therapy. Genotypes 1 and 4 are less responsive to IFN-based treatment than are the other genotypes. ${ }^{9}$ Infection with one genotype does not confer immunity against others, and concurrent infection with two strains is possible. In most of these cases, one of the strains removes the other from the host in a short time. ${ }^{10}$

\section{Natural history}

The natural history of HCV infection has been very difficult to assess because of the usually silent onset of the acute phase as well as the frequent paucity of symptoms during the early stages of chronic infection. Since the interval between infection and the development of cirrhosis can exceed 30 years, few prospective studies have been performed. Acute infection leads to chronic infection in the majority of persons, and spontaneous clearance of viremia once chronic infection has been established is rare. ${ }^{11}$ Approximately 75\%-85\% of infected patients do not clear the virus by 6 months, and chronic hepatitis develops. Cirrhosis develops in approximately $10 \%-15 \%$ of individuals with chronic hepatitis $\mathrm{C}$ infection. ${ }^{8-12}$ The progression to cirrhosis is often clinically silent, and some patients are not known to have hepatitis $\mathrm{C}$ until they present with the complications of end-stage liver disease or hepatocellular carcinoma (HCC).

\section{Clinical manifestation}

Acute hepatitis $\mathrm{C}$ refers to the first 6 months after infection with HCV although symptoms may appear within 1 day if infection was caused by any method of intravenous injection. Between $70 \%$ and $80 \%$ of adults with acute HCV infection develop no symptoms during the acute phase, while about 20\%-30\% may develop clinical symptoms. The symptomatic onset ranges 3 to 12 weeks after exposure. ${ }^{13}$ Main symptoms consist of general cold- and flu-like symptoms, others include anorexia, weakness, fatigue, abdominal pain, jaundice, and itching. Serum alanine aminotransferase (ALT) levels begin rising 2-8 weeks after exposure, and often reach levels of greater than ten times the upper limits of normal. In the serum HCV RNA can be detected within 1-2 weeks after exposure; ${ }^{14}$ their level rises rapidly during the first few weeks, and then peaks between $10^{5}$ to $10^{7} \mathrm{IU} / \mathrm{mL}$. In self-limited acute hepatitis $\mathrm{C}$, symptoms can last several weeks and subside as ALT and HCV RNA levels decline. The antibody to HCV becomes positive near the onset of symptoms, approximately 3-15 weeks after exposure. The anti-HCV assay detects greater than $90 \%$ of $\mathrm{HCV}$ infections after the initial 3 months. 
Loss of HCV RNA, which indicates a hepatitis cure, occurs in fewer than $20 \%$ of patients. Fulminant hepatic failure due to acute $\mathrm{HCV}$ infection may happen in patients with underlying chronic hepatitis $\mathrm{B}$ (CHB) virus infection. ${ }^{15}$

The risk of $\mathrm{CHC}$ infection is high; about $75 \%$ of patients present persistence of HCV RNA in the blood for at least 6 months after onset of acute infection - most of these will have persistently elevated ALT in follow-up. Once chronic infection is established, there is a very low rate of spontaneous clearance. Clinically it is often asymptomatic, and it is mostly discovered accidentally. Generalized signs and symptoms associated with $\mathrm{CHC}$ include fatigue, flu-like symptoms, joint pains, itching, sleep disturbances, appetite changes, nausea, and depression. The natural course of $\mathrm{CHC}$ varies considerably from one person to another. Among untreated patients, roughly one-third progress to liver cirrhosis in less than 20 years. Another third progress to cirrhosis within 30 years. The remainder of patients appear to progress so slowly that they are unlikely to develop cirrhosis within their lifetimes. Factors that have been reported to influence the rate of HCV disease progression include age (increasing age is associated with more rapid progression), gender (males have more rapid disease progression than females), race (African Americans appear to have a higher rate of $\mathrm{CHC}$ infection than Caucasian and Hispanic whites), alcohol consumption (associated with an increased rate of disease progression), HIV or HBV coinfection (associated with a markedly increased rate of disease progression), and fatty liver (the presence of fat in liver cells has been associated with an increased rate of disease progression). ${ }^{2}$ Most patients do not have abnormal physical examination findings until they develop portal hypertension or decompensated liver disease.

\section{Extrahepatic manifestations associated with $\mathrm{CHC}$ infections}

The HCV is a hepatotropic virus but its manifestations can extend beyond the liver; extrahepatic manifestations (EHM) have been reported in as much as $40 \%-74 \%$ of chronic HCV-infected patients (Table 1 shows the main extrahepatic manifestations); sometimes several EHM could represent the first signal of an $\mathrm{HCV}$ infection in asymptomatic patients.

Patients with CHC commonly have immunologic features including circulating autoantibodies and deposits of immune complexes in various tissues outside the liver; this may represent a major pathogenic pathway for extrahepatic disorders in the course of HCV infection.

The main targets outside the liver are the central nervous system, bone marrow, lymphonodes, monocytes, macrophages, spleen, endocrine glands, and skin cells; therefore, $\mathrm{HCV}$ infection can determine numerous extrahepatic manifestations. Often these are more serious than the hepatic disease itself and are present even in patients with persistently normal ALT levels.

\section{Interleukins}

Interleukins are a group of cytokines (secreted proteins/ signaling molecules) that were first seen to be expressed by white blood cells (leukocytes). They are pivotal in managing the positive and negative signals required to generate and shape a protective inflammatory response. The function of the immune system depends in a large part on interleukins, and rare deficiencies of a number of them have been described, all featuring autoimmune diseases or immune deficiency. The majority of interleukins are synthesized by helper CD4+ T lymphocytes, as well as through monocytes, macrophages, and endothelial cells. They promote the development and differentiation of T, B, and hematopoietic cells.

\section{IL-27}

IL-27 is a type 1 cytokine, and is a member of the IL-6/ IL-12 cytokine family, also encompassing IL-12 and IL-23 (Figure 1). Like these cytokines, IL-27 has profound effects on T-cells and acts on innate immune cells. ${ }^{28}$ It is a heterodimeric cytokine that consists of two subunits IL-27 p28 and EpsteinBarr virus (EBV)-induced gene 3 (EB13) (Figure 2A). IL-27 consists of an IL-12 p35-related protein p28, and an IL-12 p40-related protein, EBV-induced gene EBI3, which has been previously identified as one of molecules induced by EBV infection. ${ }^{29,30}$ In vitro, IL-27 has profound biological effects in costimulation of human and mouse naïve CD4+ T cells; these involve proliferation and IFN- $\gamma$ production in synergy with IL-12. ${ }^{29}$ It is secreted by antigen-presenting cells, strongly acts on $\mathrm{T}$ cells, and also stimulates innate immune cells. Interleukin-27 acts on naïve CD4+ T cells and plays pivotal roles as a proinflammatory cytokine to promote the early initiation of type 1 helper differentiation and also as an anti-inflammatory cytokine to limit the $\mathrm{T}$ cell hyperactivity and production of proinflammatory cytokines. Recent studies revealed that IL-27 plays an important role in CD8+ T cells. Cytotoxic T lymphocytes (CTLs) also play a critical role in the control of various cancers and infections, and therefore the molecular mechanisms of CTL generation are a critical issue in designing antitumor immunotherapy and vaccines which augment the development of functional and longlasting memory CTLs. ${ }^{31} \mathrm{~A}$ functional CD8+ T cell response is an essential component of the adaptive immune response 


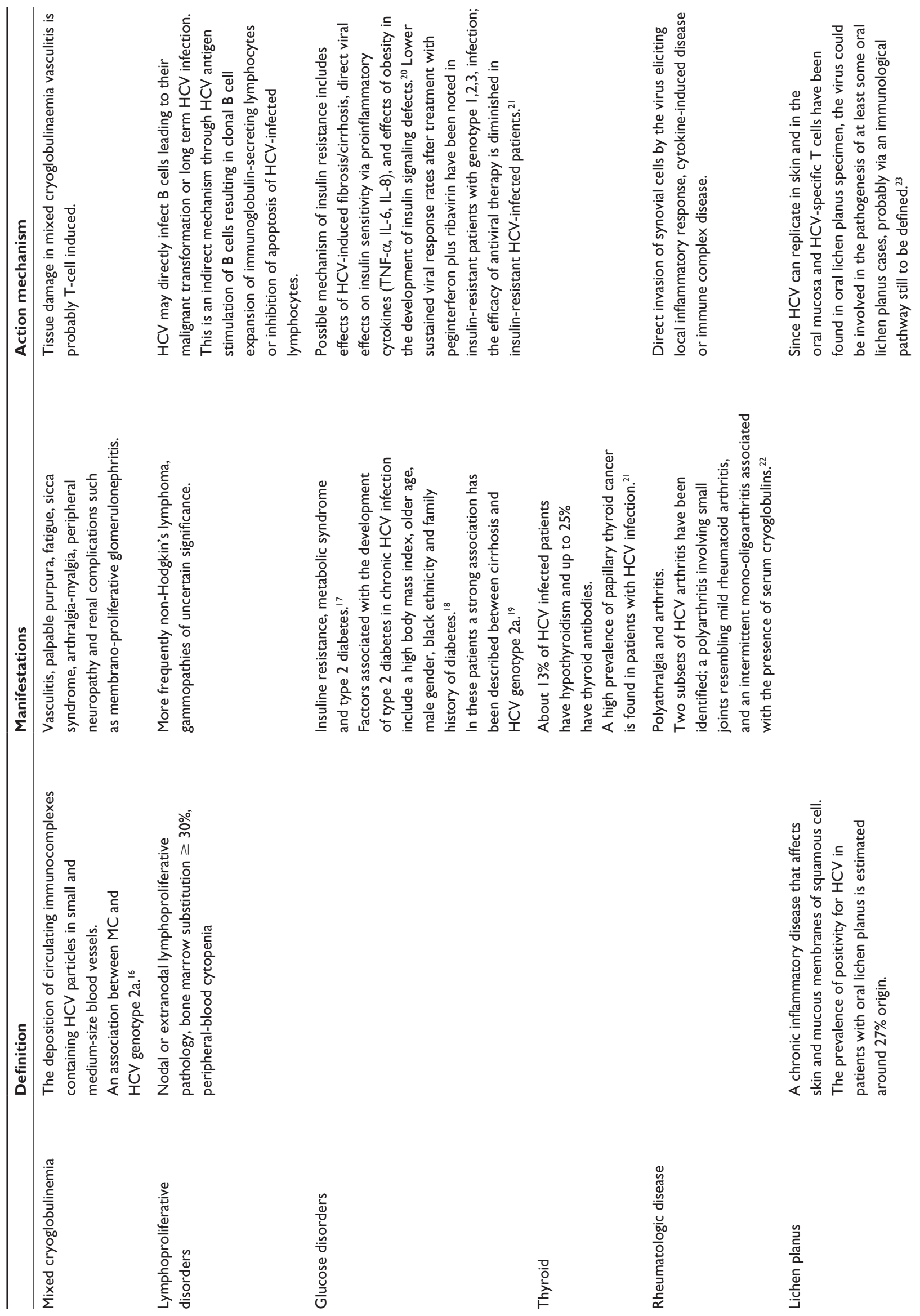


to various cancers, and bacterial and viral pathogens. ${ }^{32}$ Upon engagement with an antigen (Ag), naïve CD8+ T cells rapidly expand and differentiate into effector $\mathrm{CD} 8+\mathrm{T}$ cells, producing cytokines such as IFN and the effector molecules perforin and granzyme B. ${ }^{33}$

IL-27 p28 is believed to have a four-helix bundle cytokine-like topology and EBI3 resembles the soluble cytokine receptor-like molecules. ${ }^{29}$

Examination of complementary DNA (cDNA) libraries indicated that IL-27 p28 and EB13 are coordinately expressed predominantly by activated macrophages and dendritic cells. ${ }^{28,29}$ While the regulation of IL-27 expression has not been studied in great detail, it is clear that signaling via toll-like receptors (TLR) is a key inducer of IL-27. EB13 and IL-27 p 28 are not always expressed together by the same cells, and some factors preferentially induce one or other components of IL-27. ${ }^{34,35}$ EB13 was found to be expressed by human intestinal epithelial cells, but their known partner proteins (namely p28 and IL-12 p40, respectively) were not present; furthermore, EB13 is very highly expressed in the placenta, where IL-27 p28 is absent. ${ }^{36}$

Class I cytokine receptors are usually comprised of $\alpha$ and $\beta$ heterodimers. The $\alpha$ subunit is the primary cytokine binding protein, while the $\beta$ subunit is for high affinity binding and signal transduction. IL-27 receptor (IL-27R) is comprised of two signaling molecules, IL-27R $\alpha$ and gp130 (Figure 2B).

IL-27R $\alpha$, also known as WSX-1 or T cell cytokine receptor (TCCR), has two tyrosine residues that can be phosphorylated in humans. In mice it has three tyrosine residues, one of which is conserved. Human IL-27R $\alpha$ has a $63 \%$ sequence match with murine IL-27R $\alpha$. Human IL-27R $\alpha$ contains seven N-linked glycosylation sites, while murine IL-27R $\alpha$ has only five. IL-27R $\alpha$ is very similar to IL-12 $\beta 1 R$ in that it also lacks an immunoglobulin (Ig) domain, indicating that IL-12 $\beta R 1$ might also be a signaling partner with gp130. ${ }^{30}$

Both IL-27R $\alpha$ and gp130 receptor subunits have signaling domains, but they do not signal independently. ${ }^{37}$ IL-27R $\alpha$ expression is found in naïve and memory B cells but not in germinal center B cells. ${ }^{38}$ Alternatively activated macrophages, induced by IL-4 and IL-13, express IL-27R $\alpha$ while classically activated macrophages do not. ${ }^{39}$ In naïve $\mathrm{T}$ cells, IL-27R $\alpha$ expression is low. Its expression is high in effector and memory T cells. IL-2 suppresses the expression of IL-27R $\alpha$ nonactivated CD4 T cells in a dose-dependent manner. ${ }^{40}$ Resting NK, NKT, and T regulatory (TReg) cells express high levels of IL-27 receptors. Upon stimulation, naïve $\mathrm{T}$ cells greatly enhance the expression of IL-27R $\alpha$, while NK and NKT reduce IL-27R $\alpha$ expression. ${ }^{40}$ 


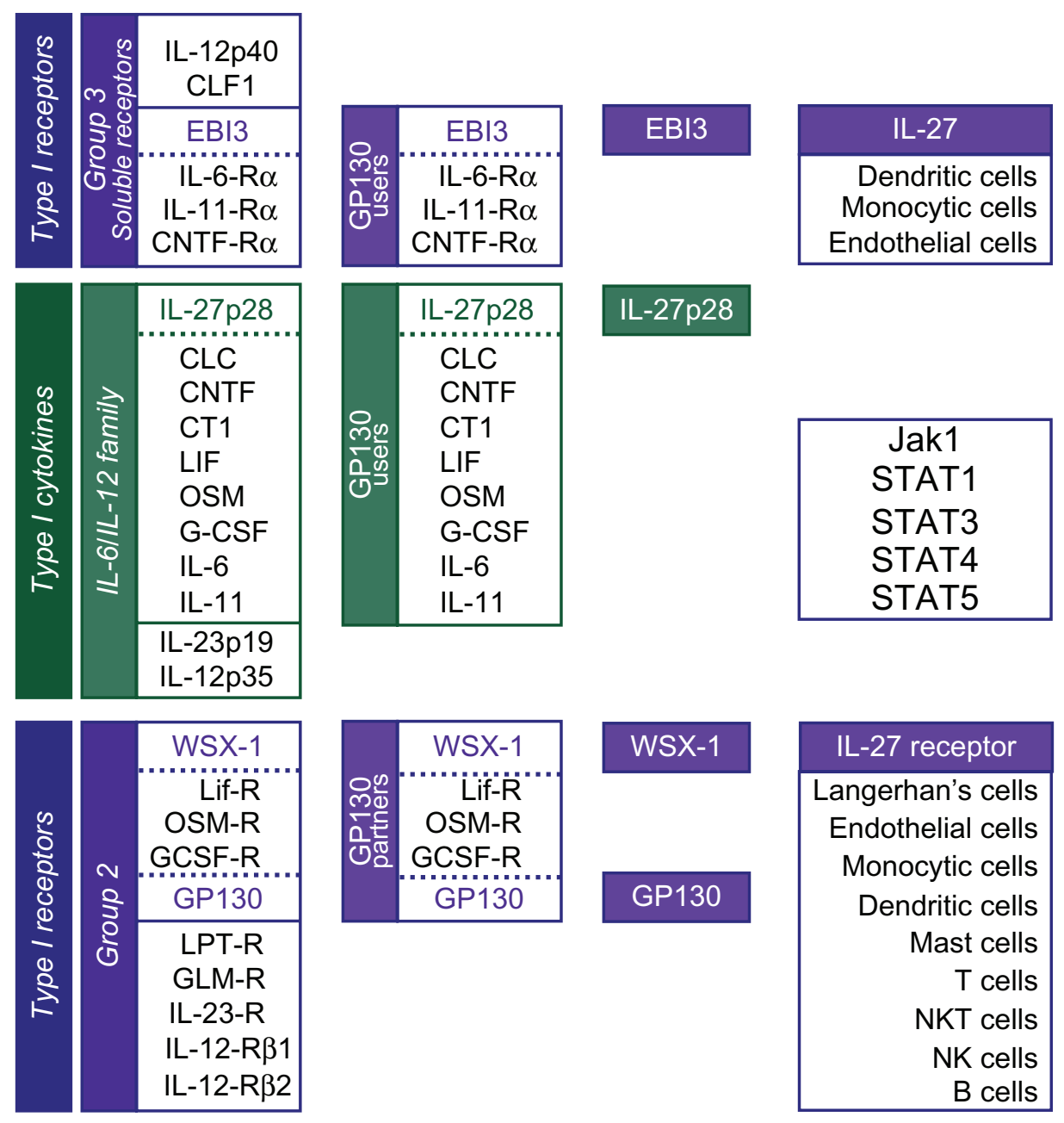

Figure I Phylogeny and expression of IL-27 and IL-27R. IL-27 is the association of an IL-6/IL-I2 family cytokine (IL-27 p28) with a group 3 soluble cytokine receptor (EBI3). IL-27R is the pairing of two group 2 cytokine receptors (gP I 30 and WSX-I). Although co-expression of both IL-27R subunits can be detected in a variety of immune cell types, production of IL27 has only been reported for endothelial cells, dendritic cells, and monocytes. Binding of IL-27 to IL-27R induces phosphorylation JakI, STATI, STAT3, STAT4, and STAT5. Because this figure is meant to emphasize general similarities in structure and receptor usage between IL-27 and other IL-6/IL-I2 family cytokines, the physical distances between individual cytokines and receptors do not reflect genetic relatedness. For a detailed account of the molecular phylogeny of all type I cytokines and receptors, see the review by Boulay et al. ${ }^{57}$ Reprinted from Immunity, Vol 19, Issue 2, Boulay et al, Molecular Phylogeny within Type I Cytokines and Their Cognate Receptors, Pp. I59-163, Copyright (2003), with permission from Elsevier.

Abbreviations: IL, interleukin; STAT, sustained signal transducer and activator of transcription.

\section{IL-27 and HCV}

The janus kinase (JAK) signal transducer and activator of the transcription pathway is critical for signal transduction by cytokines. JAK proteins associate with the domains of cytokine receptors and become activated by phosphorylation upon ligand binding. Subsequently, JAKs phosphorylate STAT transcription factors, allowing them to form dimers and translocate to the nucleus where they can induce transcription of effector genes. ${ }^{41}$ IL-27 induces STAT1 and STAT3 phosphorylation in naïve CD4+ T cells. ${ }^{34,42}$ Identification of gp130 as part of the receptor complex for IL-27 strongly supports this finding; both STAT1 and in particular STAT3 are known to be tyrosine phosphorylated in response to gp130 engagement. As a consequence of ligand binding, cytokine receptors in this family are typically phosphorylated by receptor-associated kinases on defined tyrosine-based motifs in the cytoplasmic region of the receptor. These phosphorylated tyrosine based motifs in turn serve as docking sites for the Src homology 2 domains of STAT proteins, which subsequently will be tyrosine phosphorylated themselves. Tyrosine phosphorylation of STATs is a requirement for nuclear translocation and transcriptional activity. ${ }^{43}$ The only tyrosine-based phosphorylation motif in the cytoplasmic domain of WSX-1 is GYEKHF. This sequence closely resembles the STAT motif found in the cytoplasmic region of IFN- $\gamma \mathrm{R}$ (GYDKPH), which strongly and selectively activates tyrosine phosphorylation of STAT $1 .{ }^{4}$ 
A

\section{B}

\section{IL-27}

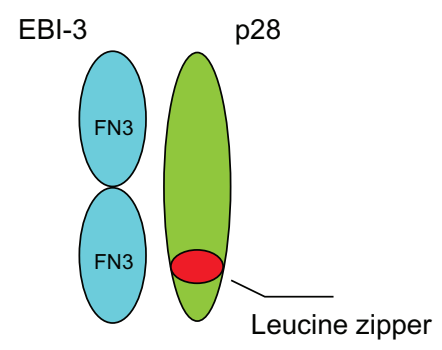

\section{IL-27R} gp130

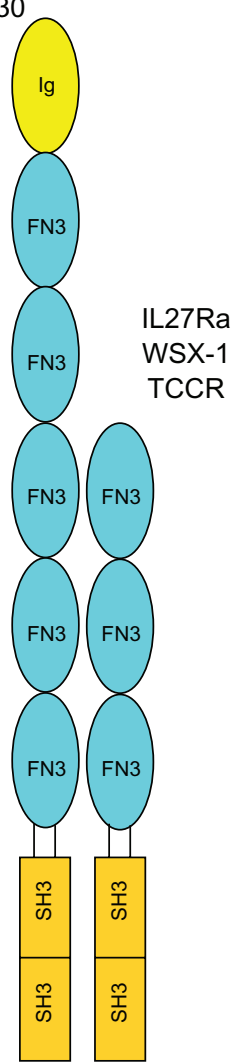

Figure $2 \mathrm{IL}-27$ and IL-27 receptors. ${ }^{58}$ (A) IL-27 is comprised of two subunits, EBI-3 and p28. EBI-3 has two fibronectin type 3 domains, and p28 has a leucine zipper motif. (B) IL-27R is comprised of gpI 30 and IL-27R $\alpha$. gp I 30 belongs to the IL-6 receptor family. IL-27R $\alpha$ is also called WSX-I orTCCR. Both chains have intracellular signaling domains. Reproduced from Carl JW, Bai XF. IL-27: its roles in the induction and inhibition of inflammation. Int J Clin Exp Pathol. 2008; I (2): I 17-123.

Abbreviation: IL, interleukin.

Because gp130 activation leads to strong activation of STAT3 and relatively weaker activation of STAT $1,{ }^{45}$ it might be expected that in the IL-27R complex WSX-1 mostly contributes to STAT1 tyrosine phosphorylation and gp130 to STAT3 tyrosine phosphorylation (Figure 3).

Although IL-27 can have proinflammatory effects, most data shows the dominant role of IL-27 being immunosuppressive. Most studies have investigated the effects of IL-27 on CD4+ T-cells, and not much is known about possible effects of IL-27 on other cell types. IL-27 was shown to promote $\mathrm{T}$ helper 1 (TH1) responses through the induction of the transcription factors T-bet, up-regulation of IL-12R $\beta 2$, and IFN- $\gamma$ production and suppression of the TH2 transcription factor GATA3 (Figure 4). ${ }^{29,46}$

IL-27 is a member of a small family of potent immune regulatory cytokines that includes, besides IL-27, IL-12 and IL-23. 29,47,48 All three cytokines are produced by activated antigen presenting cells of the monocyte/macrophage/

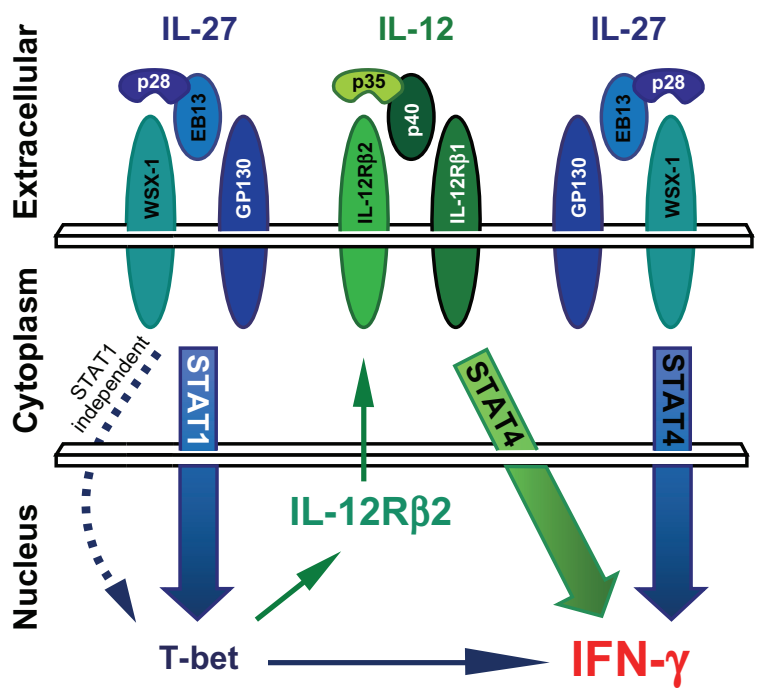

Figure 3 IL-27 can enhance interferon production through induction of T-bet and activation of STAT4. ${ }^{59}$ The binding of IL-27 to the extracellular domain of IL-27R leads to the activation of STATI and STAT4. Phosphorylated STATI migrates from the cytoplasm to induce transcription of T-bet in the nucleus. T-bet then promotes the development of type I immune responses through transactivation of the IFN gene and induction of IL-I2R 2. STAT4 phosphorylation, induced by IL-I2R or IL27R signaling, can further enhance IFN transcription and secretion. ${ }^{59}$

Reproduced from Villarino AV, Huang E, Hunter CA. Understanding the pro- and anti-inflammatory properties of IL-27. J Immunol. 2004;173(2):715-720. Copyright 2004. The American Association of Immunologists, Inc.

Abbreviations: IL, interleukin; IFN, interferon; STAT, sustained signal transducer and activator of transcription.

dendritic cell lineage. Identification of the complete IL-27 signal-transducing receptor complex has allowed us to search for cells that co-express both receptors and thus can potentially respond to IL-27 stimulation. Unlike the receptors

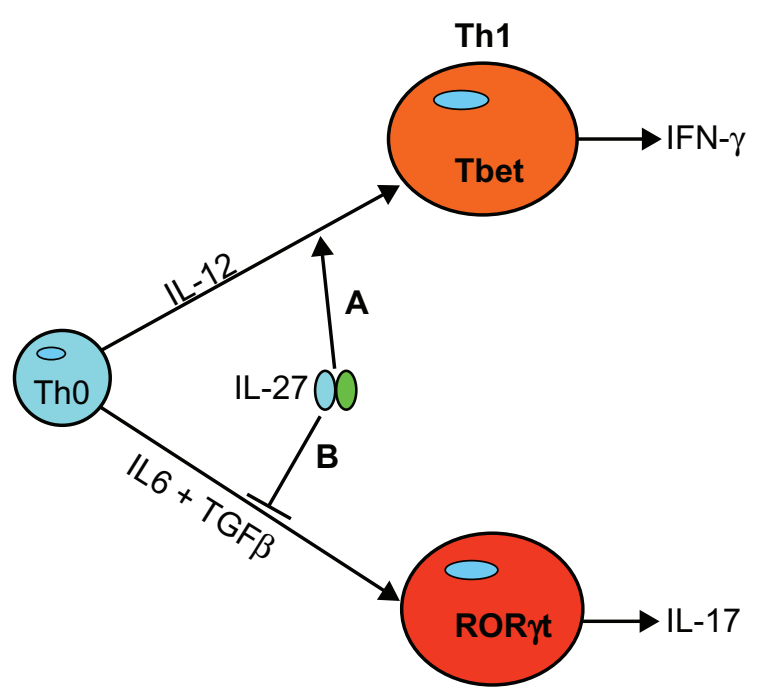

Figure 4 IL-27 promotes Th I but inhibits Th I 7 cell differentiation. ${ }^{58}(\mathbf{A})$ IL-27 promotes näive $T$ cells $(T h 0)$ to differentiate into Thl effectors characterized by expression of transcription factor T-bet and IFN- $\gamma$. (B) IL-27 inhibits CD4 T cell differentiation into ThI7 effectors characterized by expression of transcription factor ROR $\gamma \mathrm{t}$ and IL-17. This model is largely based on the results obtained from IL-27R $\alpha-I-$ mice.

Reproduced from Carl JW, Bai XF. IL-27: its roles in the induction and inhibition of inflammation. Int J Clin Exp Pathol. 2008; I (2): I I7-123.

Abbreviations: IFN, interferon; IL, interleukin. 
for IL-12 and IL-23, expression of the receptor subunits of IL-27 appears much less restricted; WSX-1 and gp130 are co-expressed on a variety of cells and tissues. This observation indicates that IL-27, besides specifically acting on naïve CD4+ T cells and NK cells, ${ }^{29}$ can be expected to have additional immune regulatory functions.

Human mast cells respond to IL-27 through STAT activation, leading to increased expression of a subset of inflammatory cytokines. Interestingly, secretion of these inflammatory cytokines occurs in the absence of a general degranulation response, indicating cytokine-specific rather than generic mast cell-activating activity. Mast cells are well recognized as key mediators of allergic reactions triggered by the release of inflammatory cytokines, histamines, and arachidonic acid metabolites through degranulation and are not primarily known for their role in propagation of an immune response to bacterial challenge (Figure 5).

Co-expression of the two IL-27R components WSX-1 and gp130 was also found on monocytes. Because activated monocytes produce IL-27, as well as its close relatives IL-12 and IL-23, an immediate consequence would be IL-27-dependent autocrine stimulation. Tyrosine phosphorylation of STAT1 and STAT3 was shown in response to IL-27 stimulation. This implies that IL-27 can stimulate monocytes in an autocrine manner. Analysis of the target genes downstream of IL-27 signaling in human primary monocytes indicates that IL-27 induces inflammatory cytokines in these cells. In particular, IL-27 significantly induced the expression of IL-18 mRNA, a cytokine that, in combination with IL-12, ${ }^{49}$ plays a key role in the induction of IFN- $\gamma$ by activated CD4 T cells. This suggests that IL-27 not only synergizes directly with IL-12 in the production of IFN- $\gamma$, but can also enhance immune responses via induction of IL-18 in activated monocytes. The IL-27R WSX-1 and gp130 are present on a variety of immune cells involved in both innate and adaptive defense mechanisms. WSX-1/gp130 double-positive cells include NK cells, dendritic cells, monocytes, mast cells, and B and $\mathrm{T}$ cells, and functional consequences of IL-27 stimulation have already been demonstrated for several of these

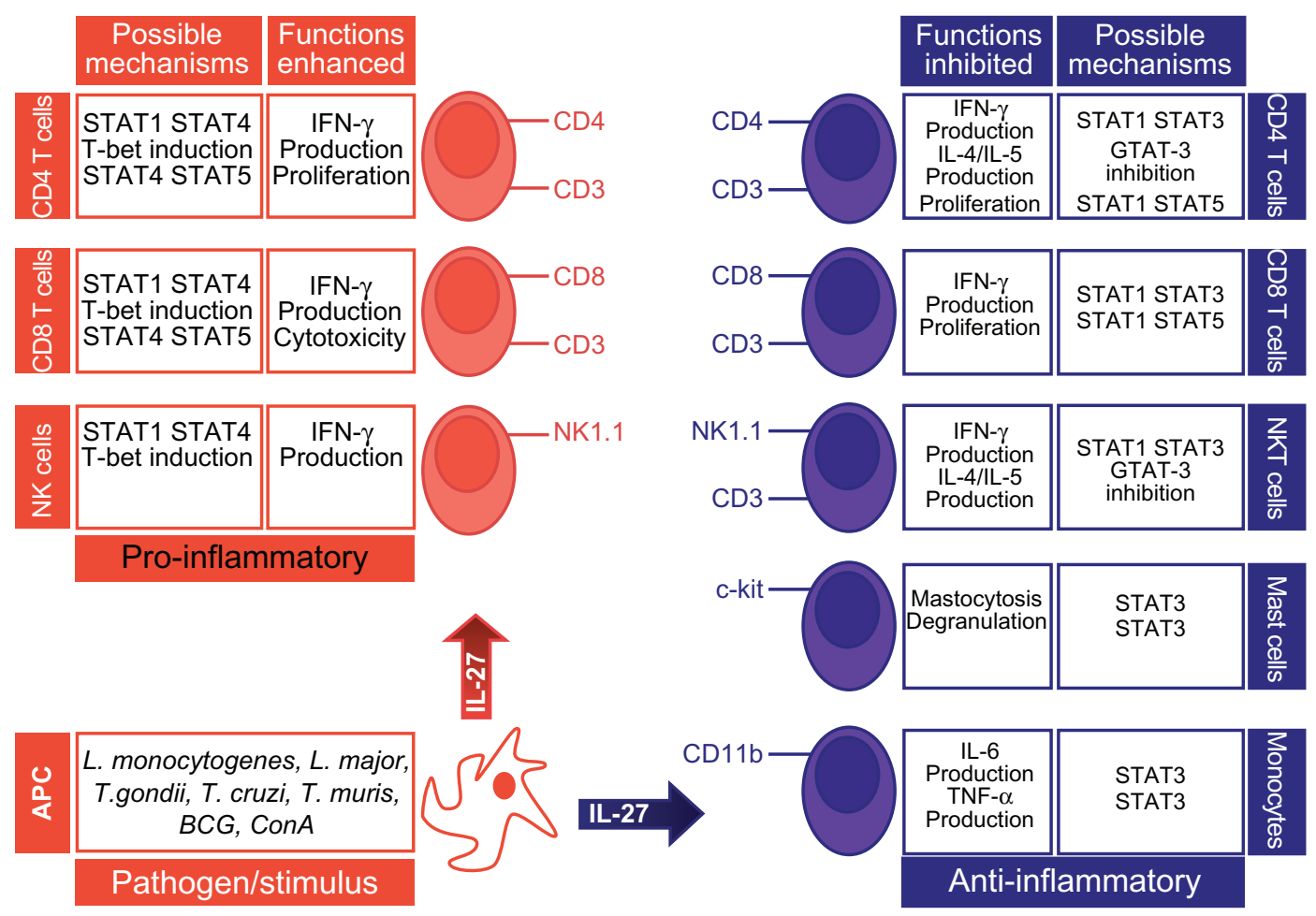

Figure 5 The pro- and anti-inflammatory properties of IL-27/IL-27R. ${ }^{59}$ IL-27 expression can be induced by a variety of inflammatory stimuli. However, IL-27 itself can have either pro- or anti-inflammatory effects on innate and adaptive elements of immunity. In T cells, IL-27 can promote or inhibit T cell effector functions. Similarly, IL-27 induces the production of IFN by NK cells but suppresses cytokine production by NKT cells in vivo. Increased monocyte and mast cell activity has been reported in the absence of WSX-I, and it is likely that IL-27R signaling may inhibit the functions of these myeloid cells. Although the molecular mechanisms for the proinflammatory effects of IL-27 are better characterized (Figure 2), several anti-inflammatory mechanisms can be proposed based on the Jak/STAT family members activated by IL-27R signaling. Activation of STATI, STAT3, and STAT5 can inhibit effector functions in an array of cell types, while IL-27-dependent GATA-3 inhibition may also play a role in the suppression of type 2 immunity. Reproduced from Villarino AV, Huang E, Hunter CA. Understanding the pro- and anti-inflammatory properties of IL-27. J Immunol. 2004;I73(2):7I5-720. Copyright 2004. The American Association of Immunologists, Inc.

Abbreviations: CD, cluster of differentiation; APC, antigen presenting cells; STAT, sustained signal transducer and activator of transcription; IFN, interferon; NK, natural killer; NKT, natural killer T; BCG, Bacille Calmette-Guerin. 
cell types. This data indicates an active role of IL-27 as a regulator in the coordination of innate as well as adaptive immune responses. ${ }^{37}$

Recent reports suggest that IL-27 can have antiviral activities in peripheral blood mononuclear cells, CD4+ T cells, and macrophages and can inhibit human immunodeficiency virus 1 replication. ${ }^{50,51}$ A recent study, published in 2007, demonstrated that IL-27 displays anti-avian influenza virus properties in the hepatoma cell line, HepG2; IL-27 induced phosphorylation of STAT1 and STAT3 in these cells. The data suggests that IL-27 may affect HCV replication in hepatocytes. Another study evaluated the impact of IL-27 on HCV replication using the Huh7.5 cell, an HCV permissive cell line. ${ }^{52}$

A previous study has shown that IL-27 significantly induces IFN-inducible antiviral genes such as myxovirus protein 1, 2'-5'-oligoadenylate synthetase 2 and RNAdependent protein kinase in macrophages, suggesting that IL-27 inhibits human immunodeficiency virus, influenza virus, and $\mathrm{HCV}$ replication by eliciting an IFN-like response. ${ }^{50}$ It has been demonstrated that IL-27 inhibits avian influenza virus replication in the HepG2 cell with the induction of myxovirus protein. The induction of myxovirus protein was not associated with the activation of IFNs in the cell. Thus, it is predicted that the mechanism by which IL-27 inhibits HCV in the hepatoma cell line is similar to that by IFN. This data confirms that IL-27 can elicit an IFN-like response, in fact the inhibition of $\mathrm{HCV}$ in the hepatoma cell line is similar to that by IFN. IL-27 at $10 \mathrm{ng} / \mathrm{mL}$ induced the activation of STAT1 and STAT3 in HCV-infected cells and significantly inhibited $\mathrm{HCV}$ replication without any impact on cell viability, while IL-27 at $100 \mathrm{ng} / \mathrm{mL}$ inhibited HCV with reduction of cell viability. The result from the neutralization assay illustrated that the mechanism by which IL-27 inhibits $\mathrm{HCV}$ replication may induce the production of IFN from hepatocytes. ${ }^{50,53-55}$

IL-27 acts on hepatocytes and hepatoma cells and displays IFN-like signaling in these cells in the same way that the antiviral effects of IL-27 observed in immune cells indicate that treatment with IL-27 could be used in the therapy of HCV infection..$^{51,52}$

IL-27 may be, therefore, a potential candidate for studies on combination therapies against hepatitis $\mathrm{C}$. The standard care for a CHC infection is a combination therapy of IFN- $\alpha$ plus ribavirin. For a standard treatment, the response rate is approximately $50 \%$ for patients with HCV genotype 1 and about $80 \%$ for genotypes 2 and 3 . For the development of future therapies, interest is focusing on combination therapies with different classes of anti-HCV drugs such as protease or polymerase inhibitors. Furthermore, novel IFN-based products are being developed. ${ }^{52}$

Liver inflammation is most often induced by viral infections, alcohol, drugs or chemical intoxication. Generally, it is associated with liver fibrosis, a wound-healing response to liver injury. ${ }^{54}$ Among the hepatic cell types, hepatic stellate cells are most important for this process. Activated hepatic stellate cells migrate and proliferate at the site of injury and perpetuate the inflammation. A key factor for the transformation of quiescent hepatic stellate cells into fibrogenetic myofibroblasts is the cytokine transforming growth factor- $\beta .^{56}$

Taken together, IL-27 may exert antiviral cytokines against HIV-1, avian influenza virus, and other viral infections.

IL-27 is capable of inhibiting replication of $\mathrm{HCV}$, as described previously. Since IL-27 inhibits replication of HIV-1 and HCV, achieving a better understanding of the role of IL-27 in regulation of gene activation and mechanism of the antiviral effect may help in the development of a novel immunotherapeutic strategy for $\mathrm{HCV}$ and $\mathrm{HCV} / \mathrm{HIV}$ coinfection as well as for other infectious diseases. ${ }^{57}$

In conclusion, it seems that IL-27 is capable of inhibiting replication of $\mathrm{HCV}$, thus these results suggest that IL-27 may be used in the therapy of HCV infection. However, very few studies have focused on human IL-27 and its involvement in and/or applicability to human viral disease, and it is clear that much remains to be learned about this cytokine.

\section{Disclosure}

The authors report no conflicts of interest in this work.

\section{References}

1. World Health Organization. Hepatitis C (online fact sheet). Available at: http://www.who.int/mediacentre/factsheets/fs164/en/. Geneva, Switzerland; Jun 2011

2. Chen SL, Morgan TR. The natural history of hepatitis C virus (HCV) infection. Int J Med Sci. 2006;3(2):47-52.

3. Tohme RA, Holmberg SD. Is sexual contact a major mode of hepatitis $\mathrm{C}$ virus transmission? Hepatology. 2010;52(4):1497-1505.

4. Kato N. Genome of human hepatitis C virus (HCV): gene organization, sequence diversity, and variation. Microb Comp Genomics. 2000; 5(3):129-151

5. Pestova TV, Shatsky IN, Fletcher SP, Jackson RJ, Hellen CU. A prokariotic-like mode of cytoplasmatic eukaryotic ribosome binding to the initiation codon during internal translation initiation of hepatitis $C$ and classical swine fever virus RNAs. Genes Dev. 1998;12(1):67-83.

6. Dubuisson J. Hepatitis C virus proteins. World J Gastroenterol. 2007; 13(17):2406-2415.

7. Simmonds P, Holmes EC, Cha TA, et al. Classification of hepatitis $\mathrm{C}$ virus into six major genotypes and a series of sybtypes by phylogenetic analysis of the NS-5 region. J Gen Virol. 1993;74(Pt 11) 2391-2399. 
8. NIH Consensus Statement on Management of Hepatitis C: 2002. NIH Consensus and State-of-the-Science Statements. 2002;19(3):1-46. Available at: http://consensus.nih.gov/2002/2002HepatitisC2002116 html.htm. Accessed October 26, 2011.

9. Simmonds P. Genetic diversity and evolution of hepatitis C virus 15 years on. $J$ Gen Virol. 2004;85(Pt 11):3173-3188.

10. Laskus T, Wang LF, Radkowski M, et al. Exposure of hepatitis $\mathrm{C}$ virus (HCV) RNA-positive recipients to HCV RNA-positive blood donors results in rapid predominance of a single donor strain and exclusion and/or suppression of the recipient strain. JVirol. 2001;75(5): 2059-2066.

11. EASL International Consensus Conference on Hepatitis C, Paris 26-28, February 1999, consensus statement. J Hepatol.1999;30(5):956-961.

12. Lauer GM, Walker BD. Hepatitis C virus infection. $N$ Engl J Med. 2001;345(1):41-52.

13. Thimme R, Oldach D, Chang KM, Steiger C, Ray SC, Chisari FV. Determinants of viral clearance and persistence during acute hepatitis $\mathrm{C}$ virus infection. $J$ Exp Med. 2001;194(10):1395-1406.

14. Farci P, Alter HJ, Wong D, et al. A long term study of hepatitis C virus replication in non-A non-B hepatitis. N Engl J Med. 1991;325(2): 98-104.

15. Farci P, Alter HJ, Shimoda A, et al. Hepatitis C virus-associated fulminant hepatic failure. N Engl J Med. 1996;335(9):631-634.

16. Franguel L, Musset L, Cresta P, Cacoub P, Huraux JM, Lunel F. Hepatitis $\mathrm{C}$ virus genotypes and subtypes in patients with hepatitis C, with and without cryoglobulinemia. J Hepatol. 1996;25(4):427-432.

17. Mason AL, Lau JY, Hoang N, et al. Association of diabetes mellitus and chronic hepatitis C virus infection. Hepatology. 1999;29(2):328-333.

18. Caronia S, Taylor K, Pagliaro L, et al. Further evidence for an association between non-insulin dependent diabetes mellitus and chronic hepatitis C virus infection. Hepatology. 1999;30(4):1059-1063.

19. Sheikh MY, Choi J, Quadri I, Friedman JE, Sanyal AJ. Hepatitis C virus infection: molecular pathways to metabolic syndrome. Hepatology. 2008;47(6):2127-2133.

20. Poustchi H, Negro F, Hui J, et al. Insulin resistence and response to therapy in patients infected with chronic hepatitis $\mathrm{C}$ virus genotypes 2 and 3. J Hepatol. 2008;48(1):28-34.

21. Lormeau C, Falgarone G, Roulot D, Boissier MC. Rheumatologic manifestations of chronic hepatitis C infection. Joint Bone Spine. 2006; 73(6):633-638.

22. Carrozzo M, Quadri R, Latorre P, et al. Molecular evidence that the hepatitis C virus replicates in the oral mucosa. J Hepatol. 2002;37(3): 364-369.

23. Smyth CM, McKiernan SM, Hagan R, et al. Chronic hepatitis C infection and sicca syndrome: a clear association with HLA DQB1*02. Eur J Gastroenterol Hepatol. 2007;19(6):493-498.

24. Ramos-Casals M, Garcia-Carrasco M, Cervera R, et al. Th1/Th2 cytokine imbalance in patients with Sjogren syndrome secondary to hepatitis C virus infection. Semin Arthritis Rheum. 2002;32(1): $56-63$.

25. O'Reilly FM, Darby C, Fogarty J, et al. Porphyrin metabolism in hepatitis C infection. Photodermatol Photoimmunol Photomed. 1996;12(1): 31-33.

26. Weissenbom K, Ennen JC, Bokemeyer M, et al. Monoaminergic neurotransmission is altered in hepatitis $\mathrm{C}$ virus infected patients with chronic fatigue and cognitive impairment. Gut. 2006;55(11):1624-1630.

27. Batten M, Ghilardi N. The biology and therapeutic potential of interleukin 27. J Mol Med. 2007;85(7):661-672.

28. Pflanz S, Timans JC, Cheung J, et al. IL-27, a heterodimeric cytokine composed of EBI3 and $\mathrm{p} 28$ protein, induces proliferation of naive $\mathrm{CD} 4+$ T cells. Immunity. 2002;16(6):779-790.

29. Sprecher CA, Grant F, Baumgartner JW, et al. Cloning and characterization of a novel class I cytokine receptor. Biochem Biophys Res Commun. 1998;246(1):82-90.

30. Noriko M, Izuru M, Masae O, et al. A pivotal role for Interleukin-27 in $\mathrm{CD} 8^{+} \mathrm{T}$ cell functions and generation of cytotoxic $\mathrm{T}$ lymphocytes. J Biomed Biotechnol. 2010;2010:605483.
31. Kaech SM, Wherry EJ, Ahmed R. Effector and memory T-cell differentiation: implications for vaccine development. Nat Rev Immunol. 2002;2(4):251-262.

32. Bender $\mathrm{H}$, Wiesinger MY, Nordhoff $\mathrm{C}$, et al. Interleukin-27 displays interferon-gamma-like functions in human hepatoma cells and hepatocytes. Hepatology. 2009;50(2):585-591.

33. Hibbert L, Pflanz S, De Waal Malefyt R, Kastelein RA. IL-27 and IFN $\alpha$ signal via STAT1 and STAT3 and induce T-bet and IL-12R-beta-2 in naive T cells. J Interferon Cytokine Res. 2003;23(9):513-522.

34. Sonobe Y, Yawata I, Kawanokuchi J, Takeuchi H, Mizuno T, Suzumura A. Production of IL-27 and other IL-12 family cytochines by microglia and their subpopulations. Brain Res. 2005;1040(1-2):202-207.

35. Devergne O, Hummel M, Koeppen H, et al. A novel interleukin-12 p40-related protein induced by latent Epstein-Barr virus infection in B lymphocytes. J Virol. 1996;70(2):1143-1153.

36. Pflanz S, Hibbert L, Mattson J, et al. WSX-1 and glycoprotein 130 constitute a signal-transducing receptor for IL-27. J Immunol. 2004; 172(4):2225-2231.

37. Larousserie F, Charlot P, Bardel E, et al. Differential effects of IL-27 on human B cell subsets. J Immunol. 2006;176:5890-5897.

38. Ruckerl D, Hessmann M, Yoshimoto T, et al. Alternatively activated macrophages express the IL-27 receptor alpha chain WSX-1. Immunobiology. 2006;211:427-436.

39. Villarino AV, Larkin J 3rd, Saris CJ, et al. Positive and negative regulation of the IL-27 receptor during lymphoid cell activation. J Immunol. 2005; 174:7684-7691.

40. Leonard WJ, O'Shea JJ. Jaks and STATs: biological implications. Annu Rev Immunol. 1998;16:293-322.

41. Takeda A, Hamano S, Yamanaka A, et al. Cutting edge: role of IL-27/ WSX-1 signaling for induction of T-bet through activation of STAT1 during initial Th1 commitment. J Immunol. 2003;170(10):4886-4890.

42. Ihle JN. The Stat family in cytokine signaling. Curr Opin Cell Biol. 2001;13(2):211-217.

43. Cook JR, Jung V, Schwartz B, Wang P, Pestka S. Structural analysis of the human interferon gamma receptor: a small segment of the intracellular domain is specifically required for class I major histocompatibility complex antigen induction and antiviral activity. Proc Natl Acad Sci US A. 1992;89(23):11317-11321.

44. Heinrich PC, Behrmann I, Muller-Newen G, Schaper F, Graeve L. Interleukin-6-type cytokine signalling through the gp130/Jak/STAT pathway. Biochem J.1998;334(Pt 2):297-314.

45. Lucas S, Ghilardi N, Li J, de Sauvage FJ. IL-27 regulates IL-12 responsiveness of naive CD4+ $\mathrm{T}$ cells through Stat1-dependent and -independent mechanisms. Proc Natl Acad Sci USA. 2003;100(25): 15047-15052.

46. Trinchieri G. Interleukin-12 and the regulation of innate resistance and adaptive immunity. Nat Rev Immunol. 2003;3(2):133-146.

47. Oppmann B, Lesley R, Blom B, et al. Novel p19 protein engages with IL-12p40 to form a cytokine, IL-23, with biological activities similar as well as distinct from IL-12. Immunity. 2000;13(5):715-725.

48. Chang JT, Segal BM, Nakanishi K, Okamura H, Shevach EM. The costimulatory effect of IL-18 on the induction of antigen-specific IFNgamma production by resting T cells is IL-12 dependent and is mediated by up-regulation of the IL-12 receptor beta2 subunit. Eur J Immunol. 2000;30(4):1113-1119.

49. Imamichi T, Yang J, Huang DW, et al. IL-27, a novel anti-HIV cytokine, activates multiple interferon inducible genes in macrophages. AIDS. 2008;22(1):39-45.

50. Fakruddin JM, Lempicki RA, Gorelick RJ, et al. Noninfectious papilloma virus-like particles inhibit HIV-1 replication: implications for immune control of HIV-1 infection by IL-27. Blood. 2007;109(5): 1841-1849.

51. Zeuzem S. Interferon-based therapy for chronic hepatitis C: current and future perspectives. Nat Clin Pract Gastroenterol Hepatol. 2008; 5(11):610-622.

52. Bataller R, Brenner DA. Liver fibrosis. J Clin Invest. 2005;115(4): 1100. 
53. Bender H, Wiesinger MY, Nordhoff $\mathrm{C}$, et al. Interleukin-27 displays interferon-gamma-like functions in human hepatoma cells and hepatocytes. Hepatology. 2009;50(2):585-591.

54. Galligan CL, Murooka TT, Rabbar R, Baig E, Majchrzak-Kita B, Fish EN. Interferons and viruses: signalling for supremacy. Immunol Res. 2006;35(1-2):27-40.

55. Gressner AM, Weiskirchen R. Modern pathogenetic concepts of liver fibrosis suggest stellate cells and TGF-beta as major players and therapeutic targets. J Cell Mol Med. 2006;10(1):76-99.
56. Frank AC, Zhang X, Katsounas A, Bharucha JP, Kottilil S, Imamichi T. Interleukin-27, an Anti-HIV-1 Cytokine, Inhibits Replication of Hepatitis C Virus. J Interferon Cytokine Res. 2010;30(6):427-431.

57. Boulay JL, O'Shea JJ, Paul WE. Molecular phylogeny within type I cytokines and their cognate receptors. Immunity. 2003;19(2):159-163.

58. Carl JW, Bai XF. IL-27: its roles in the induction and inhibition of inflammation. Int J Clin Exp Pathol. 2008;1(2):117-123.

59. Villarino AV, Huang E, Hunter CA. Understanding the pro- and antiinflammatory properties of IL-27. J Immunol. 2004;173(2):715-720.

International Journal of Interferon, Cytokine and Mediator Research

\section{Publish your work in this journal}

The International Journal of Interferon, Cytokine and Mediator Research is an international, peer-reviewed, open-access, online journal. The focus of the journal is to publish original research, reports, editorials, reviews and commentaries on all aspects of interferon, cytokine and mediators of inflammation from labora- tory science to therapeutic indications and clinical studies. The manuscript management system is completely online and includes a very quick and fair peer-review system, which is all easy to use. Visit http://www.dovepress.com/testimonials.php to read real quotes from published authors.

Submit your manuscript here: http://www.dovepress.com/international-journal-of-interferon-cytokine-and-mediator-research-journal 